\title{
Regulations and Standards for TV White Space
}

\author{
${ }^{* 1}$ Vijaya G. Rajeshwarkar, ${ }^{2}$ Shekhar M. Jagade, ${ }^{3}$ P. Chandrashekar Reddy, ${ }^{4}$ Tanuja S. Dhope \\ 1,3 Jawaharlal Technological University Hyderabad, ${ }^{2}$ STB's College of Engg. Tuljapur \\ ${ }^{4}$ BVUCOE, Pune \\ *Email: v.rajeshwarkar@gmail.com
}

Received: $13^{\text {th }}$ December 2018, Accepted: $13^{\text {th }}$ February 2019, Published: $3^{\text {th }}$ June $_{2019}$

\begin{abstract}
Digital dividend has created much of free spectrum in TV bands from 470- $790 \mathrm{MHz}$ This free spectrum is called TV white Space and it can be used to solve spectrum scarcity problem. The frequency spectrum is allocated to licensed users by the government authorities of that particular country. International Telecommunication Union-Radio communications have started allowing unlicensed users to use the white spaces. But there are regulations on using these white spaces. This paper focuses on various regulating authorities, standards used for opportunistically accessing the spectrum. The basic requirement is there should not be any harmful interference to the incumbent user. The prospective of Cognitive radio improves spectral efficiency, by making secondary users opportunistically access spectrum gaps, left by primary users. In this paper different methods to identify spectrum gaps and use it efficiently, are discussed. Coexistence issues of multiple SUs are also discussed in brief.
\end{abstract}

\section{Keywords}

Coexistence; Primary User; Regulation; Secondary User; Spectrum Sharing; TV White Space.

\section{Introduction}

Radio spectrum is very costly and scarce natural resource. By 2020 there will be requirement for more than $1720 \mathrm{MHz}$ [1] of RF spectrum [ITU-R] [M-2078], as there is increase in communication devices. The increase in wireless devices is exponential whereas the RF spectrum available will be fixed. Thus there will be spectrum crunch which is mainly due to static spectrum allocation. This static allocation leads to unutilized or underutilized spectrum. Spectrum is allotted statically to the licensed users, so it cannot be used by unlicensed users. But it has been reported from various studies that spectrum is underutilized in almost all frequency bands at a given time and location. This unutilized spectrum is called "White space" or "Spectrum hole" or "Spectrum opportunity".

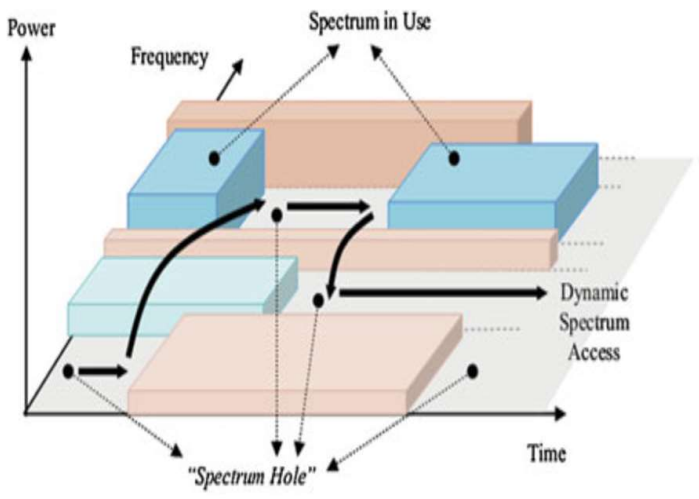

Figure 1: Spectrum Hole and Dynamic Spectrum Access [Source 2]

TV channels which are not being used by licensed users at a particular time and at a particular location are called TV White Spaces. A lot of TV spectrum has become available as a result of Digital Dividend (analog to digital transition). Due to excellent propagation characteristics and less infrastructure requirements, TV spectrum is useful for rural and underdeveloped areas.

Licensed users of TV spectrum are called as Primary users (PUs) or Incumbent users (e.g. Digital Terrestrial Television and wireless microphones) and the unlicensed users of TV spectrum are called Secondary Users (SUs) or Opportunistic users [3]. Cognitive radio is recognized as a gifted solution for this spectrum scarcity and it works on the principle of Dynamic spectrum access [4].

Organization of paper is as follows. Section II deals with various regulatory authorities and regulations on using TV Band Devices (TVBDs) is discussed, section III explains Cognitive techniques to access fallow spectrum. Standards used for accessing TV white spaces are considered in section IV. In section V 
coexistence issues are explained and section VI concludes the paper.

\section{Regulatory Authorities of Radio Spectrum:}

International Telecommunication Union (ITU) supervises the radio spectrum globally, but the government agencies in each country provide regulations for the use of radio spectrum in that country, which has regulating authority.

\section{A. Regulatory Authorities}

Federal Communications Commission (FCC) is the regulatory body in United States. Regulating body in United Kingdom is Office of Communications (OFCOM), European Conference of Postal and Telecommunications Administrations (CEPT) in Europe, Japanese Ministry of Internal Affairs and Communications (MIC) in Japan, Info-communications Development Authority of Singapore (IDA) in Singapore, Industry Canada in Canada, and The Independent Communications Authority of South Africa (ICASA) in South Africa.

Wireless Planning and Coordination (WPC) wing is the National radio regulatory authority in India. Allocation of each part of spectrum for diverse radio services information is provided in National Frequency Allocation Plan (NFAP) [5].

Many countries like US, UK, Singapore, Japan have already formulated regulations for TV white space use. Recently South Africa has prescribed regulations for use of TV white spaces. As of now there are no regulations framed in India for the for using TV White spaces. IIT Bombay is carrying out much of the research on TV white spaces in India.

\section{B. Spectrum Allocation}

As per International Table of Frequency Allocations of the Radio Regulations Articles (Edition 2012), there is region-wise allocation of radio services. As per this allocation, three regions has been formed-1, 2 \& 3 .

- In ITU Region 1 - 470 to $790 \mathrm{MHz}$ is for

Broadcasting only (E.g. Europe).

- In ITU Region $2-470$ to $512 \mathrm{MHz}$ is used for

Broadcasting as Primary service and Mobile \&

Fixed services as Secondary (E.g. USA).

- In ITU Region $3-470$ to $585 \mathrm{MHz}$ is allotted

for Fixed, Mobile \& Broadcasting as

primary services.

India is a part of ITU Region 3.

Range of radio spectrum is from $3 \mathrm{kHz}$ to $3000 \mathrm{GHz}$, but spectrum up to $50 \mathrm{GHz}$ is only exploited.

TV broadcasting services are operated in VHF (54 to $216 \mathrm{MHz}$ ) and UHF (470 to $806 \mathrm{MHz}$ ) bands in analog and digital mode [6].

a. TV Channels in USA:

RF frequency spectrum 54 to $806 \mathrm{MHz}$ is assigned to 2 to $69 \mathrm{TV}$ channels, with channel bandwidth of $6 \mathrm{MHz}$ (54-72 MHz, 76-88 MHz, 174-216 MHz, and 470-806 MHz). VHF channels are 2-13 \& UHF cannels are 14-51.

The $698-806 \mathrm{MHz}$ band is allocated to channels 52-69 and is divided into "Lower $700 \mathrm{MHz}$ band" from 698-746 MHz and "Upper $700 \mathrm{MHz}$ band" from 746-806 MHz [7].

b. TV Channels in UK:

In UK Digital Terrestrial Television transmitters use radio frequency spectrum between $470-790 \mathrm{MHz}$ (UHF band). TV channels 20 to 60 are the target bands for TV white space. Channel bandwidth is 8 $\mathrm{MHz}$ [7].

c. Spectrum Allocation for Terrestrial Broadcasting in India:

Frequency Spectrum in the band $470-890 \mathrm{MHz}$ is reserved for Fixed, Mobile and Broadcasting services, as per NFAP-2011. Digital broadcasting services operate in the band 585-698 MHz band. Frequency band 698-806 MHZ has been reserved for International Mobile Telecommunications Advanced (IMT-A) [8].

VHF Band I (47-68 MHz) - This band consists of two channels with $7 \mathrm{MHz}$ bandwidth. Out of 1415 transmitters of Doordarshan, 8 transmitters transmit in this band.

VHF band III (174-230 MHz) (ch. 5-12) - 1034 transmitters operate in this band consisting of 8 channels each with $8 \mathrm{MHz}$ bandwidth.

UHF Band IV (470-590 MHz) (Ch.21-35) - There are 373 transmitters transmitting in this band, consisting of 15 channels, each with $8 \mathrm{MHz}$ bandwidth.

UHF Band V (590-806 MHz) - No channel is assigned for analogue TV transmission by Doordarshan, in this band. 


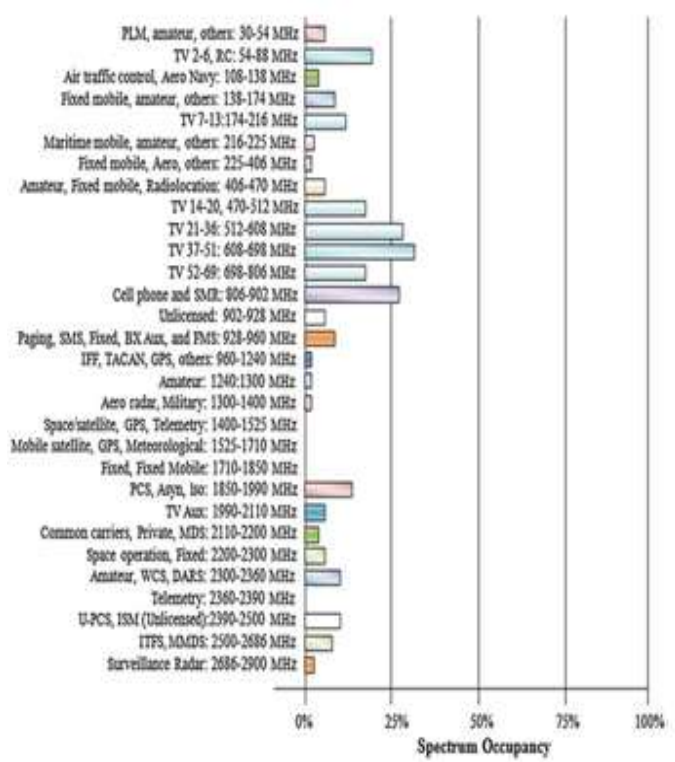

Figure 2: Spectrum Occupancy in RF Bands [Source 2]

\section{Regulations for TV Band Devices}

As per FCC devices operating in TV white space are termed as TV Band Devices (TVBDs). According to FCC these devices can be classified as:

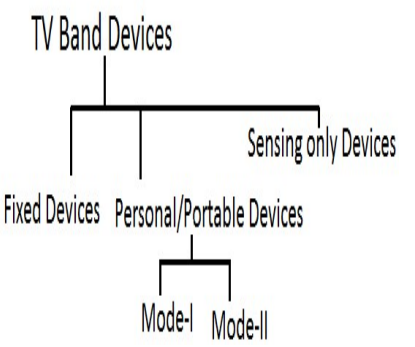

Figure 3: Classification of TV Band devices

\begin{tabular}{|c|c|c|c|c|c|c|}
\hline $\begin{array}{l}\text { TVBD } \\
\text { Type }\end{array}$ & Operating Channels & $\begin{array}{l}\text { Max. } \\
\text { EIRP }\end{array}$ & $\begin{array}{ll}\text { Database for } \\
\text { Incumbent } \\
\text { protection }\end{array}$ & $\begin{array}{l}\text { Detection } \\
\text { Threshold }\end{array}$ & PSD & $\begin{array}{l}\text { In-service } \\
\text { Monitoring }\end{array}$ \\
\hline Fixed & $\begin{array}{l}\text { Operate on channels } \\
2-51 \text { except ch.3, } 4 \\
\& 37 . \\
\text { Not allowed on } \\
\text { adjacent channels. }\end{array}$ & $<4 \mathrm{~W}$ & $\begin{array}{l}\text { Geolocation/Dat } \\
\text { abase }\end{array}$ & $-114 \mathrm{dBm}$ & $\begin{array}{l}16.7 \\
\mathrm{~mW} / 100 \\
\mathrm{kHz}\end{array}$ & $\begin{array}{l}\text { Database } \\
\text { access atleast } \\
\text { once }\end{array}$ \\
\hline Mode I & $\begin{array}{l}\text { Operate on channels } \\
21-51 \text { (except ch.37) } \\
\text { Can operate on } \\
\text { adjacent channels. }\end{array}$ & $\begin{array}{l}<100 \mathrm{~m} \\
\mathrm{~W} \\
<40 \mathrm{~mW} \\
\text { (on } \\
\text { adjacent } \\
\text { channel) }\end{array}$ & $\begin{array}{l}\text { Fixed or Mode II } \\
\text { device }\end{array}$ & $-114 d \mathrm{dBm}$ & $\begin{array}{l}0.67 \mathrm{~mW} / \\
100 \mathrm{kHz} \\
\text { (adjacent } \\
\text { channel) } \\
1.67 \mathrm{~mW} / 10 \\
0 \mathrm{kHz} \text { (non- } \\
\text { adjacent } \\
\text { channel) }\end{array}$ & $\begin{array}{lr}\text { Atleast } & \text { once } \\
\text { every } & 60 \\
\text { seconds } & \end{array}$ \\
\hline
\end{tabular}




\begin{tabular}{|c|c|c|c|c|c|c|}
\hline Mode II & $\begin{array}{l}\text { Operate on channels } \\
21-51 \text { (except ch.37) } \\
\text { Allowed to operate } \\
\text { on adjacent channel }\end{array}$ & $\begin{array}{l}<100 \mathrm{~m} \\
\mathrm{~W} \\
\\
<40 \mathrm{~mW} \\
\text { (on } \\
\text { adjacent } \\
\text { channel }\end{array}$ & $\begin{array}{l}\text { Geolocation/data } \\
\text { base access }\end{array}$ & $-114 \mathrm{dBm}$ & $\begin{array}{l}0.67 \mathrm{~mW} / \\
100 \mathrm{kHz} \\
\text { (adjacent } \\
\text { channel) } \\
1.67 \mathrm{~mW} / 10 \\
0 \mathrm{kHz} \text { (non- } \\
\text { adjacent } \\
\text { channel) }\end{array}$ & $\begin{array}{l}\text { Atleast for } \\
\text { every } 100 \mathrm{~m} \\
\text { move and } \\
\text { one time in a } \\
\text { day. }\end{array}$ \\
\hline $\begin{array}{l}\text { Sensing } \\
\text { only }\end{array}$ & $\begin{array}{l}\text { Allowed to operate } \\
\text { on adjacent channel }\end{array}$ & $\begin{array}{l}<50 \mathrm{~mW} \\
<40 \mathrm{~mW} \\
\text { (on } \\
\text { adjacent } \\
\text { channel) }\end{array}$ & $\begin{array}{l}\text { Spectrum } \\
\text { sensing }\end{array}$ & $-114 \mathrm{dBm}$ & & $\begin{array}{l}\text { Once every } \\
60 \text { seconds }\end{array}$ \\
\hline
\end{tabular}

TABLE I: Technical Requirements for TVBDs as per FCC[11]

Fixed devices are not permitted to operate on channels adjacent to TV broadcast channels. They operate on the VHF channels except channels 3-4 and on UHF channels except channels 36-38. Personal/portable devices operate on the channels adjacent to TV channels, but with reduced EIRP which is 40mW. They are not permitted on the VHF channels, but can operate on UHF channels except channels 14-20 \& 37 [7]. For TVBDs Height Above Average Terrain (HAAT) is allowed to be 30 meters.

Personal/Portable devices which use sensing only without geolocation/database can t transmit up to $50 \mathrm{~mW}$ EIRP. These devices should scan the channel every 60 seconds and vacate the channel in 2 seconds once the primary user is detected [10].

Cognitive Radio (CR) has been observed as a promising technology to deal with spectrum shortage and exploitation of underutilized spectrum using dynamic re-use of the frequency spectrum allocated to incumbent users.

In 1999, Dr.Mitola [12] [13] proposed the concept of CR and Haykin defined it. Cognitive Radio can be defined as [14]: "Cognitive Radio is a radio system employing technology that allows the system to obtain knowledge of its operational and geographical environment, established policies and its internal state, to dynamically and autonomously adjust its operational parameters and protocols according to its obtained knowledge in order to achieve predefined objectives and to learn from the results obtained".

The key idea of CR is to embrace spectrum sharing through Dynamic Spectrum Access (DSA).

D. Spectrum Sharing

Spectrum sharing includes four steps:

1. Spectrum Sensing: This step is performed to detect presence of white spaces. Secondary users (Cognitive users) continuously sense the frequency spectrum for presence of primary users, in time, frequency and space domain.

2. Spectrum Allocation: Here spectrum hole will be allotted to secondary users. Efficient spectrum allocation algorithms are designed to improve efficient utilization of spectrum.

3. Spectrum Access: Primary users (PUs) access the spectrum with highest priority. Efficient spectrum access algorithms are required to avoid interference of SUs with PUs.

4. Spectrum Handoff: SUs must quit the spectrum immediately and switch to other spectrum when a PU appears, in order to avoid collision. If the SUs geographical location changes (without change in PUs geolocation), SUs have to switch to suitable frequency bands. SUs must switch to other frequency bands if their communication requirements cannot be met [4]

Amount of TV white space depends on Height Above Average Terrain (HAAT), transmission power of SUs, protection margin of PUs, separation of licensed and unlicensed users, etc.

\section{Cognitive Techniques for Opportunistic Spectrum Access}

As per FCC, the basic requirement while utilizing white space is no hurtful interference to the primary users. Three principal methods can be used to identify which segment of the TV band is available at specific time and/or location.

1. Spectrum Sensing: In this technique secondary users constantly observe the channel for primary user's presence or absence. If no primary user is found i.e. channel is vacant, sensing is applied to adjoining channels to resolve the restrictions on transmission power in adjoining channel, if any.

Spectrum sensing requires sensing threshold, repetition of re-sensing of vacant channel periodically \& sampling duration.

Advantage of using spectrum sensing is that there is no need of connection to a database or a beacon.

Following are some of the non-cooperative spectrum sensing methods:

i. Energy Detection: This is the simplest and most often used technique for spectrum sensing. Here a priori knowledge of the PUs is not required. This sensing method involves measurement of energy of 
radio waves over a certain frequency spectrum (channel) and it is compared with a predefined threshold. If the measured energy is greater than the threshold it indicates presence of PUs or else absence of PU. The threshold is calculated from noise floor of the spectrum, but as per FCC maximum threshold set is $114 \mathrm{dBm}$. This method performs poorly at low signal-to-noise ratio.

ii. Matched Filter Detection: In this method observed signal features are correlated with known signal. When there is priori knowledge of PU signal parameters such as pilot, preamble, spreading codes, etc, this method is applied. Its implementation is complex and has high energy consumption. Also priori knowledge of PU signal is needed.

iii. Cyclostationary Feature Detection: PU transmission is detected by utilizing cyclostationarity features of the received signals. Using periodicity presence of PUs can be identified. This method is complex to implement.

iv. Eigen Values Based Detection: Like energy detection, no priori knowledge of the PU signal characteristics is required here. So it is often referred to as blind detection or blind sensing.

The signal and noise information is obtained from the maximum and minimum Eigen values respectively, from the covariance matrix of the received signal. For signal detection it uses Quantized information based on Random Matrix Theories (RMT). Using RMT, both threshold and probability of false alarm are obtained. Noise uncertainty problem can be overcome using this technique.

2. Geolocation Database: As per FCC, a database containing geolocation information of PUs is created as per rules set by regulator. SUs/TVBDs should register with these databases. TVBDs should notify information about their determined location to these databases and send request to database for accessing channel. Upon reception of request from TVBD, database checks for the accessibility of TVWS in that region and notifies available channel to the TVBD. According to FCC portable TVBDs have to access database every time as the TVBD moves $100 \mathrm{~m}$ from its previous position.

3. Beacon: These are signals which are used to specify whether primary user uses a particular channel or not. Beacon signal contains information about the available channels in the coverage area of base station. Every base station broadcasts beacon signal periodically. In response to this beacon signal client broadcasts channel location. SU can transmit only if it receives beacon signal from the base station.

Different beacon setups are:

$>\quad$ Enable beacon- The channel can be used if beacon is detected.

$>\quad$ Disable beacon- Here if beacon is detected, the channel cannot be used, as it is occupied.

$>\quad$ Beacon pilot channel- Local TV channels are identified by this.

Currently geolocation database and spectrum sensing techniques are used together [15] [16] [17] [18].

IIT Bombay has proposed protocol to access TVWS geolocation database in India [19].

Wireless Standards used in TV White Spaces

Summary of few wireless standards used in TV white space will be explained here.

1. IEEE 802.22 WRAN: IEEE 802.22 Wireless Regional Area Network (WRAN) is the first IEEE 802 wireless standard developed to function in TV white space using Cognitive radio. This standard is developed to offer broadband access to regional, scarcely populated remote and rural areas within line-ofsight and non line-of-sight. It provides point-to-multipoint broadband access in rural areas up to $17-33 \mathrm{~km}$ $(\max .100 \mathrm{~km})$ from its base station (BS) to Customer Premises Equipment (CPE). This standard covers TV spectrum from 54-862 MHz It uses either spectrum sensing or geolocation/database or special beacons for incumbent protection. Orthogonal Frequency Division Multiplexing (OFDM) is used in PHY layer design with FFT size of 2048. QPSK, 16-QAM and 64-QAM modulation schemes are employed. It utilizes Time Division Multiplexing for Radio downlink and Orthogonal Frequency Division Multiple Access (OFDMA) for uplink. This standard supports channel bandwidths of 6,7 and $8 \mathrm{MHz}$ This standard uses centralized approach with one BS serving up to 512 CPEs. IEEE 802.22 supports cognitive function for protection of incumbents and coexistence of similar 802.22 devices (Self-coexistence) [11] [20] [21].

2. IEEE 802.11af: This standard called White-Fi or Super Wi-Fi was approved in Feb 2014. It allows Wireless Local Area Network (WLAN) operation in TV white space spectrum in the VHF and UHF bands between 54 and $790 \mathrm{MHz}$. It uses OFDM for PHY layer design with FFT size of 64, 128, 256 (512 \& 1024 is optional). Operating channels for this standard are 5, 10, 20 \& $40 \mathrm{MHz}$. BPSK, QPSK, 16 QAM \& 64QAM modulation schemes are used. On MAC layer it uses Carrier Sense Multiple Access with Collision Avoidance (CSMA/CA) This standard uses master, slave and peer devices to form a network. Network here operates in two modes: the master-slave mode or the peer-to-peer mode. In master-slave mode one device is considered as a master and remaining devices as slave. The master device coordinates the channel access or slave can directly communicate with master under the coordination of master. With channel reservation and distributed beaconing channel access can be coordinated in peer-to-peer network. A four way handshake is used to provide secured relationship between two devices [22]. This standard uses Orthogonal Frequency Division multiplexing (OFDM) modulation. FFT size is 128 considering maximum signal output and better system performance. Guard Interval (GI) is $1.16 \mu \mathrm{s}$ [23]. 


\section{Coexistence Issues in TV White Space}

There are regulations for using TV white spaces by SUs so that no harmful interference happens to PUs. The SUs have equal priority when accessing the white space and hence there will be interference between different SUs. There are no regulations on using same spectrum resources by various SUs. When a number of SUs try to access the same spectrum simultaneously, it is referred to as coexistence.

Coexistence issues can be classified as:

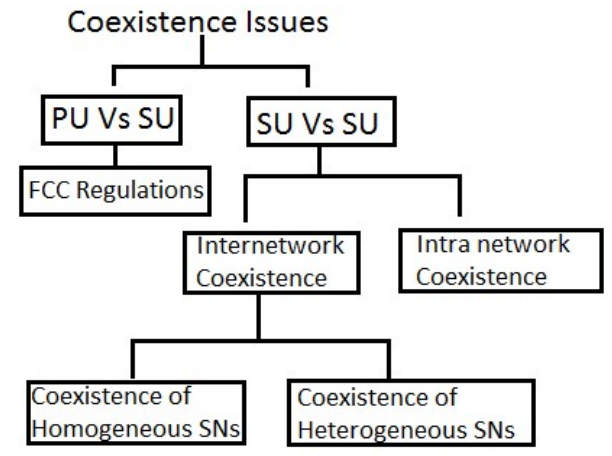

Figure 4: Classification of Coexistence Issues

Intra network coexistence is spectrum sharing among various SUs in single secondary network. Whereas inter network coexistence is sharing spectrum between SUs in dissimilar secondary networks.

Homogeneous coexistence refers to spectrum sharing or coexistence between TVBDs using same wireless technology (e.g. Coexistence between two IEEE 802.22 networks). Heterogeneous coexistence is spectrum sharing by multiple TVBDs using different wireless technology (e.g. Coexistence between IEEE 802.22 \& IEEE 802.11af) [24]. IEEE 802.19.1 standard deals with coexistence issues of multiple TVBDs.

\section{Conclusion}

As many government authorities have released the TV white space for secondary users, the problem of spectrum scarcity has been solved. Many regulations have been framed for Primary and secondary user coexistence as well as secondary and secondary user coexistence.

\section{References}

1. Report ITU-R M 2078, http://www.itu.int/dms-pub/itu-r/opb/rep/R-REP-M.2078-2006-PDF-E.pdf.

2. Lee W.Y.," Spectrum Management in Cognitive Radio Wireless Networks", a Technical report, Ph.D. thesis submitted at Georgia Institute of Technology (2009).

3. Junyi Wang, Stanislav Filin, Tuncer Baykas, M Azizur Rahman, Chunyi Song, Hiroshi Harada," A Feasible Neighbor Discovery Algorithm for Coexistence Control System over TVWS", in 2012 IEEE Wireless Communicatios and Networking Conference: Services, Applications \& Business.

4. Feng Hu, Bingchen, Kun Zhu, "Full Spectrum Sharing in Cognitive Radio Networks Toward 5G: A Survey", in IEEE Access, vol. 6, 2018.

5. Purnendu S.M. Tripathi, Ashok Chandra, Ramjee Prasad,"Deployment of Cognitive Radio in India”, in Wireless Pers. Communication (2014).

6. P.S.M. Tripathi, Ashok Chandra, Ramjee Prasad,'TV White Space Spectrum in India”, NICT 2013.

7. Boonyeon Kim,Maenjoo Lee,"Opportunities and Challenges of Using TV White Spaces-A Comparative Analysis of Approaches Among U.S.A., U.K. and S. Korea",SSRN e-journal, 12 Sept. 2014.

8. Gaurang Naik, Sudesn Singhal, Animesh Kumar \& Abhay Karandikar,"Quantitative Assessment of TV White Space in India", in National Conference of Communications, Kanpur, India, IEEE 2014.

9. Chittabrata Ghosh, Sumit Roy, Dave Cavalcanti,"Coexistence Challenges for Heterogeneous Cognitive Wireless Networks in TV White Spaes", IEEE Wireless Communications, August 2011.

10. Stephen J. Shellhammer, Ahmed K. Sadek \& Wenyi Zhang,'Technical Challenges for Cognitive Radio in TV White Space Spectrum", in 2009 Information Theory and Applications Workshop, San Diego, CA, USA.

11. Tuncer Baykas, Mark Cummings, et.al.,"Developing A Standard for TV White Space Coexistence: Technical Challenges and Solution Approaches", in IEEE Wireless Communications, Vol.19, Issue 1, Feb.2012, PP-10-22.

12. J.Mitola \& G.Q. Maguire Jr.,"Cognitive Radio:Making Software Radios more Personal”, IEEE Personal Comm., Vol.6, no.4, pp.-13-18, 1999.

13. S.Haykin,"Cognitive Radio: Brain Empowered Wireless Communications”, in IEEE Journal on selected areas in communication, Vol.23, no.2, pp. 201-200, Feb 2005.

14. ITU-R, SM. 2152 (2009) Definitions of Software Defined Radio (SDR) \& Cognitive Radio System (CRS). 
15. Siddharth Shetty, Akshay Mishra \& Abhay Karandikar,'Proposal for TV White Space Towards National Frequency Allocation Plan [NFAP] 2010, IITB, 15 Jan 2011.

16. Second Report and Order \& Memorandum Opinion Order, Nov 142008.

17. Jai Sachith Paul, Akhil P Sivan, Kumar Raushan Ratnesh \& Sreekala K.,"Effective Deployment of TV White Space for Enhancing Rural Broadband in India", in International Journal of Computer Science \& Mobile Computing, Dec 17-18, 2013, Trivendram, Kerala, India, pp. 101-107.

18. Aleksandr Zavodovski, Helsinki,'Understanding the Challenges of TV White Space Databases for Mobile Usage", May 20, 2016.

19. Soumik Ghosh, Gaurang Naik, Animesh Kumar \& Abhay karandikar,’OpenPAWS: An Open Source PAWS

\& UHF TV White Space Databse Implementation for India”, in 2015, Twenty first National Conference on Communications (NCC), IEEEXplore 16 April 2015.

20. Ermanno Pietrosemoli,'Overview of White Space Standards"

21. Demian Lekomtcev, Roman Marsalek,"Comparison of 802.11af and 802.22 standards-Physical Layer \& Cognitive Functionality", Elekrorevue, Vol.3, No.2, June 2012.

22. Standard ECMA-392, MAC and PHY for operation in TV White Space, 2nd Edition/ June 2012.

23. Jung-Sun Um, Sung-Hyun Hwang, and Byung Jang Jeong," A Comparison of PHY Layer on the Ecma-392 and IEEE 802.11 af Standards", CROWNCOM 2012, June 18-20, Stockholm, Sweden.

24. You Han, Eylen Ekici, Haris Kremo, Onur Altintas,"A Survey of MAC Issues for TV White Space Access", Elsevier, Dec.2014. 